\title{
Burnout in Sport: A Systematic Review
}

\author{
Kate Goodger, Trish Gorely, David Lavallee, \\ and Chris Harwood \\ Loughborough University
}

\begin{abstract}
The purpose of the present review was to provide an up-to-date summary of the burnout-in-sport literature. The last published reviews were in 1989 (Fender) and 1990 (Dale \& Weinberg). In order to appreciate the status of current knowledge and understanding and to identify potential future directions, the authors conducted a synthesis of published work using a systematic-review methodology. Findings comprised 3 sections: sample characteristics, correlates, and research designs and data collection. A total of 58 published studies were assessed, most of which focused on athletes $(n=27)$ and coaches $(n=23)$. Correlates were grouped into psychological, demographic, and situational factors and were summarized as positively, negatively, indeterminate, and nonassociated with burnout. Self-report measures and cross-sectional designs have dominated research. The authors conclude by summarizing the key findings in the literature and highlighting the gaps that could be filled by future research.
\end{abstract}

Burnout in the sport setting was first investigated by Caccese and Mayerberg (1984) in a study of coach burnout. Similar to many concepts in sport psychology, the original conceptualization occurred outside sport, in this case in the work domain. Herbert Freudenberger (1974) is generally considered the founding father with his study on staff burnout among volunteers at a New York drug rehabilitation clinic. Around the same time, however, Christina Maslach, a social-psychology researcher, also began to coin the term to describe a gradual process of exhaustion, cynicism, and reduced commitment among poverty lawyers. Maslach's work has continued to be instrumental in shaping the development of research in the field, and the more practitioner-based approach established by Freudenberger has forged a second tradition focused on the assessment, prevention, and treatment of the syndrome (Schaufeli \& Buunk, 2003).

In both the professional and sport settings the concept of burnout has been enormously popular and readily taken up. The media have been instrumental in popularizing the concept through (in the case of sport) sensational accounts of the dramatic demise of high-profile sports stars and the decline of young prodigies who fail to fulfill their potential. It has become a colloquialism in the sport community and among the wider fan base (Raedeke, 1997; Vealey, Armstrong, Comar, \& Greenleaf, 1998). Use of the term burnout also conjures powerful visual

The authors are with the School of Sport and Exercise Sciences, Loughborough University, Loughborough LE11 3TU UK. 
images, but, despite the vividness of such images, there remains much debate as to the definition and measurement of burnout in the sport setting (Raedeke \& Smith, 2001). Research on coaches and other sport practitioners has long employed the widely accepted conceptualization of burnout by Maslach and Jackson (1984). From this standpoint, burnout comprises three dimensions: emotional exhaustion, depersonalization, and reduced performance accomplishment. Issues concerning the appropriateness of this conceptualization for use among athlete populations have led to the development of an athlete-specific version (Raedeke, Lunney, \& Venables, 2002). Through a study conducted on swimming, Raedeke et al. defined burnout as "a withdrawal from [sport] noted by a reduced sense of accomplishment, devaluation/resentment of sport, and physical/psychological exhaustion" (p. 181). Considering the contextual differences between the sport and professional domains, Raedeke et al. offered the following description for each dimension: Physical/emotional exhaustion is associated with intense training and competition. A reduced sense of accomplishment is related to skills and abilities-athletes are unable to achieve personal goals or they perform below expectation. Sport devaluation refers to a loss of interest, a "don't care" attitude, or resentment toward performance and the sport. Physical/emotional exhaustion and a reduced sense of accomplishment reflect characteristics in the sport context that are similar to the professional context, but athletes' experiences of sport devaluation represent a marked contrast to depersonalization in the workplace. Depersonalization, originally characterized by a negative and cynical attitude toward people at work and more recently as cynicism toward work and people at work in general, has not been identified as a salient dimension in athlete burnout (Raedeke \& Smith). Sport devaluation focuses on performance and sport as a whole rather than relationships with others in this environment and, as such, replaces depersonalization. For the purpose of the review, burnout will be examined based on the three dimensions of burnout proposed by Maslach and Jackson (1984) for practitioners, including coaches, and by Raedeke et al. for athletes.

The importance of studying burnout stems principally from its impact on affected individuals and organizations through issues such as ill health of employees and absenteeism. In a 25-year review of the burnout literature, Schaufeli and Buunk (2003) outlined five categories of symptoms associated with the syndrome: affective (e.g., tearful, depressed mood, hostility), cognitive (e.g., feeling helpless, cynicism, impaired attention and memory), physical (e.g., exhaustion, illness), behavioral (e.g., absenteeism and impaired performance), and motivational (e.g., disillusionment, lack of enthusiasm). In the context of sport, the implications are not only to the health and well-being of the individual but also to their performance. Feigley (1984) extends these concerns by arguing that losses resulting from the early retirement or attrition of young elite athletes ahead of their physical and psychological prime marks both "unfulfilled human potential and a lowered quality of our national team programs" (p. 109). Withdrawal associated with burnout also has implications for the development of expertise among coaches through the early departure of coaches from the profession (Kosa, 1990).

In 2001 a special issue of the journal Psychology and Health was devoted to a review of research examining burnout in professional contexts. The principal aim of the special issue resonated in a question posed by Christina Maslach in her concluding commentary: What have we learned about burnout and health? Although several 
book chapters have been written that provide more recent summary overviews of research in sport settings (Gould \& Dieffenbach, 2002; Kallus \& Kellmann, 2000), the last published empirical reviews were by Fender (1989) and Dale and Weinberg (1990). At the time of the reviews' publications there were no empirical studies of athlete burnout (Dale \& Weinberg, 1990), and research had primarily focused on burnout in practitioners such as coaches. In the 1990s there was a shift-more investigations began exploring burnout among athletes, and a number of studies that are now considered to be classics in the field emerged (e.g., Gould, Tuffey, Udry, \& Loehr, 1996a, 1996b, 1997). In the future directions of the Fender and Dale and Weinberg reviews, the authors converged on a number of key issues they believed to be significant in moving the field forward. These are (a) agreement on an operational definition of burnout, (b) development of measurement tools and strategies for assessing burnout among athletes, (c) development of theoretical frameworks to explain burnout in sport, and (d) development of intervention strategies. There have been several advances in relation to these points, and, as a result of the length of time since the previous reviews and the advancements that have occurred, it is important for sport psychology to revisit the question: What have we learned about burnout and sport? The purpose of the current study, therefore, was to conduct a systematic review of the sport-burnout literature with a particular focus on examining the populations in which burnout has been explored, questions have been asked, and research strategies have been employed. Similar systematic reviews and meta-analyses have been conducted in the professional literature (e.g., Fothergill, Edwards, \& Burnard, 2004; Lee \& Ashforth, 1996), and through this type of review process they have offered the opportunity to consolidate findings and identify the known and the unknown (Mulrow, Cook, \& Davidoff, 1997). Specifically, the review aims to provide a summary of sample characteristics, correlates, and research designs employed up to 2005.

\section{Background to Theoretical Conceptualizations of Burnout in Sport}

In their reviews Fender (1989) and Dale and Weinberg (1990) detail that conceptual thinking about burnout in sport was guided primarily by work in the professional domain (i.e., Maslach and Jackson, 1984) and Smith's cognitive-affective model of athlete burnout (1986), the only published model at the time. In the early 1990s three other models emerged (Coakley, 1992; Schmidt \& Stein, 1991; Silva, 1990). In brief, Smith's model suggests that burnout is the product of chronic stress and parallels the stress process. It manifests itself through the relationship between situational factors, cognitive appraisal of the interaction between the person and situation, physiological responses (related to the appraisal), and behavioral responses (Dale \& Weinberg). These components are in turn influenced by motivation and personality factors. A stress-induced perspective of burnout is also central to the only coach-specific theory of burnout proposed by Kelley and colleagues (Kelley, 1994; Kelley, Eklund, \& Ritter-Taylor, 1999; Kelley \& Gill, 1993). Coakley offers a sociological explanation in which burnout is the product of sport organizations. Young athletes in such organizations experience identity foreclosure, which results in a unidimensional identity and a feeling of loss of autonomy. Schmidt and Stein 
proposed a commitment-based model and suggested that burnout is more than a simple reaction to stress; it also relates to an athlete's commitment. Athletes who experience burnout are typically involved in their sports because they "have to be" rather than "want to be." Finally, Silva outlines a model of burnout as the final stage of a continuum of overtraining and staleness and the result of a negative response or maladaptation to training.

In recent years there have been some new advances in conceptual thinking toward athlete burnout including a biopsychological perspective of stress and recovery (Kallus \& Kellmann, 2000), a failure-adaptation model (Tenebaum, Jones, Kitsantas, Sacks, \& Berwick, 2003), and a total-quality-recovery model (Kentta \& Hassmen, 1998). Central to these contemporary theories is a desire to distinguish burnout from related concepts such as overtraining and staleness that have previously been used synonymously. It should be noted, however, that these theories are not entirely original because they contain tenets of Silva's (1990) work. All theories incorporate burnout as an extreme end state resulting from maladaptation to training or insufficient recovery. The stress-and-recovery model and the total-qualityrecovery model suggest that burnout is the eventual result of chronic exposure to stress (training/nontraining) and insufficient (quality) recovery. In contrast, the failure-adaptation model proposes that it is not simply an imbalance between stress and recovery but also the interaction of events, situations, and dispositions.

\section{Method}

\section{Sources}

The search strategy used the following three main sources to locate published studies of burnout in the sports setting: (a) electronic searches of computerized databases, including SPORTDiscus, PsychLIT, First Search, Web of Science, Zetoc, Medline, and BIDS; (b) citations in papers identified by the electronic searches; and (c) hand searching of journals, including The Sport Psychologist, International Journal of Sport Psychology, Journal of Applied Sport Psychology, Journal of Sport \& Exercise Psychology, Journal of Sport Behavior, Medicine and Science in Sport and Exercise, Journal of Sports Sciences, Research Quarterly in Sport and Exercise, Journal of Sociology of Sport, and Quest. Keyword combinations used included burnout, overtraining, staleness, stress, motivation, dropout, exhaustion, athlete, coach, director, administrator, official, sport, exercise, and physical activity. Inclusion criteria were that articles must have been published in the English language and contain data specifically pertaining to burnout.

\section{Procedure}

Hard copies of publications were obtained and assessed for relevance according to the inclusion criteria. Once included, analysis of the studies followed the descriptive, semiquantitative review protocol outlined in Sallis, Prochaska, and Taylor (2000). Studies were initially coded with a bibliography number, but as independent sample populations $(k)$ were used as the unit of analysis, additional coding further distinguished samples such as male and female (M and F) and age group (e.g., 22, 
30). Data tables were constructed for sample characteristics of study populations (e.g., nationality), correlates of burnout, and research designs.

\section{Analysis}

Data tables were analyzed to create summary tables, which involved a number of stages. First, variables were selected and categorized based on the recommendation that in order for a correlate to be identified and an association determined, there must be three or more comparisons available (i.e., they had appeared in three or more independent samples). Second, the direction of associations was examined. Independent samples for each correlate were assessed and coded positive (+), negative (-), or no association (0) with burnout and indeterminate (?) when the nature of the association was unclear. Finally, a summary of the literature for each correlate was determined through a calculation of the percentage of independent samples supporting associations. Sallis et al. (2000) outlined the following classification system as a means of coding results: $0-33 \%=$ no association, $34-59 \%$ $=$ indeterminate or inconsistent, and $60-100 \%=$ positive or negative association. Sample characteristics (i.e., age, gender) were summarized using a tallying system and resulted in total counts.

Considerable debate continues concerning the inclusion of qualitative research studies in systematic reviews. Booth (2001) proposed that metasynthesis, the science of summing up, can be either quantitative or qualitative, but, to date, the criteria for a good review exhibit institutionalized quantitativism in that it is almost entirely determined by quantitative methods. Because of the limited number of qualitative studies published, we decided to integrate data from these studies with that of the quantitative part of the analysis. In an attempt to combat a potential reduction in the richness of qualitative data associated with quantitative synthesis (Weed, 2005), a narrative summary section was also provided. The symbols positive (+), negative ( - , no association ( 0$)$, and indeterminate (?) were used to indicate the direction of association between the variables that were explored in these studies and burnout.

\section{Results}

\section{General Findings}

We identified 61 published studies. Three were later excluded because of a lack of burnout data, resulting in a final count of 58. Of the studies, 27 focused on athletes, 23 on coaches, 2 on athletic directors, 2 on athletic trainers, 3 on officials, and 1 on job satisfaction of sport-center employees. Two studies (viz., Price \& Weiss, 2000; Vealey et al., 1998) reported findings for both athletes and coaches. Although these studies have been incorporated only once in the total count of burnout studies $(N=$ $58)$, they are included in the total counts for athlete $(n=27)$ and coach studies $(n$ $=23$ ) because they present separate data relating to each population group. As a result of the limited number of studies examining burnout among athletic directors, athletic trainers, officials, and sport-center employees, findings of these studies were not discussed further. The results of the review are therefore presented as 
two separate categories - athlete burnout and coach burnout - and are divided into sample characteristics, correlates, and research designs.

\section{Sample Characteristics of Athlete-Burnout Studies}

The examination of sample characteristics enabled us to gain a picture of the types of individuals who have been investigated in research and potential gaps in sampling.

Studies examining burnout among athletes comprised a total population size of 2,448, and 22 independent samples were identified. The number of independent samples was lower than the total number of studies (27) because multiple articles were published using data from the same original sample groups (viz., Gould et al., 1996a, 1996b, 1997; Raedeke, 1997; Raedeke \& Smith, 2001, Studies 1 \& 2; Raedeke \& Smith, 2004; Udry, Gould, Bridges, \& Tuffey, 1997). Samples tended to be mixed gender and included athletes from a range of competitive levels and types of sport, although individual sports have received greater attention. North American samples have historically dominated the literature, but, more recently, samples have begun to emerge from Europe and Australasia. See Table 1 for a summary of sample characteristics.

\section{Sample Characteristics of Coach-Burnout Studies}

The 23 located studies on coach burnout comprised a total population of 6,460 and 41 independent samples. Demographic information detailed in coach-burnout studies has generally been reported less consistently than in athlete studies, which has limited our ability to provide a summary of these factors. The relationship between burnout and gender has been examined more specifically in coach research, and, hence, sampling has shown a greater tendency to separate genders, enabling comparisons between them not paralleled in research on athletes. Again, a range of competitive levels and types of sports have been examined, but there is a notable absence of elite coaches. Furthermore, there are only two studies published with non-North-American-based samples (viz., Koustelias, Kellis, \& Bagitis, 1997; Omotayo, 1991). See Table 2 for a summary of sample characteristics.

\section{Correlates of Burnout}

Three types of variables were examined in the studies reviewed: psychological (athlete $=41$, coach $=20)$, demographic (athlete $=12$, coach $=20)$, and situational (athlete $=19$, coach $=20$ ). In applying Sallis et al.'s (2000) recommendation of a minimum of three independent samples for the identification of correlates, the number of actual correlates to emerge was significantly reduced (see Table 3; Contact lead author for full list of variables).

\section{Psychological Correlates of Athlete Burnout}

Analysis of the 41 psychological factors in athlete studies resulted in 13 correlates that comprised five themes: motivation, coping with adversity, response to training and recovery, role of significant others, and identity (see Table 3). 


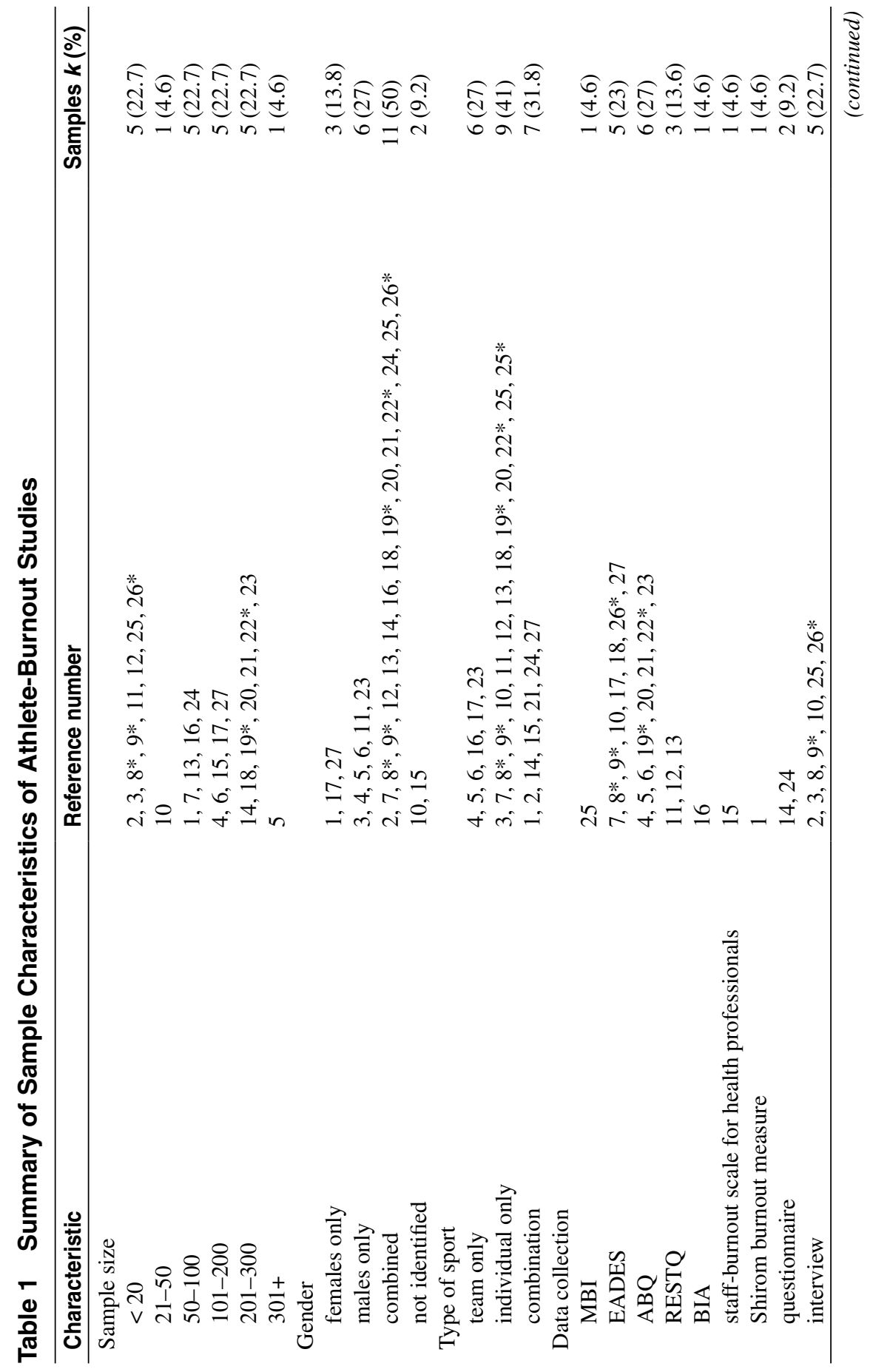




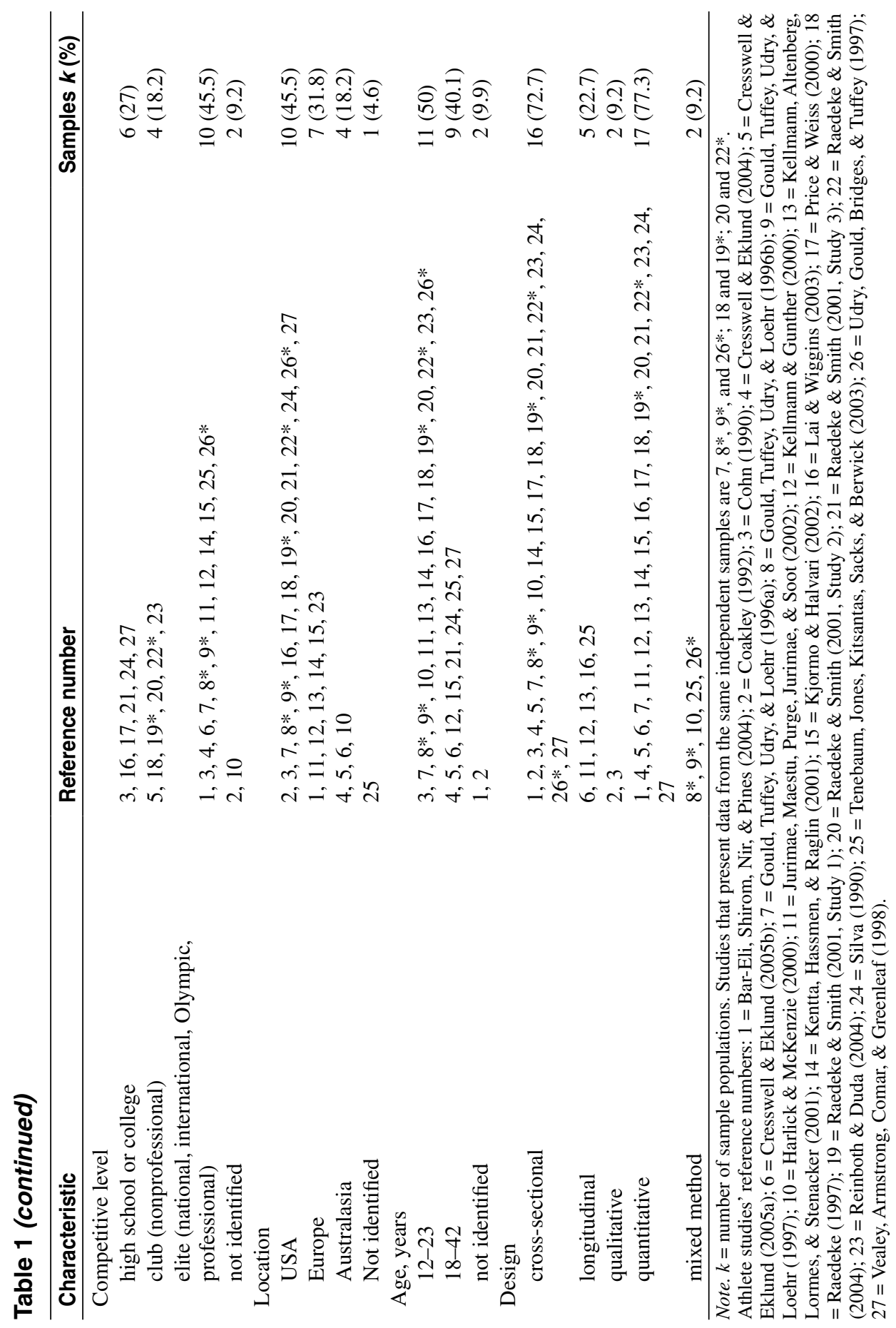




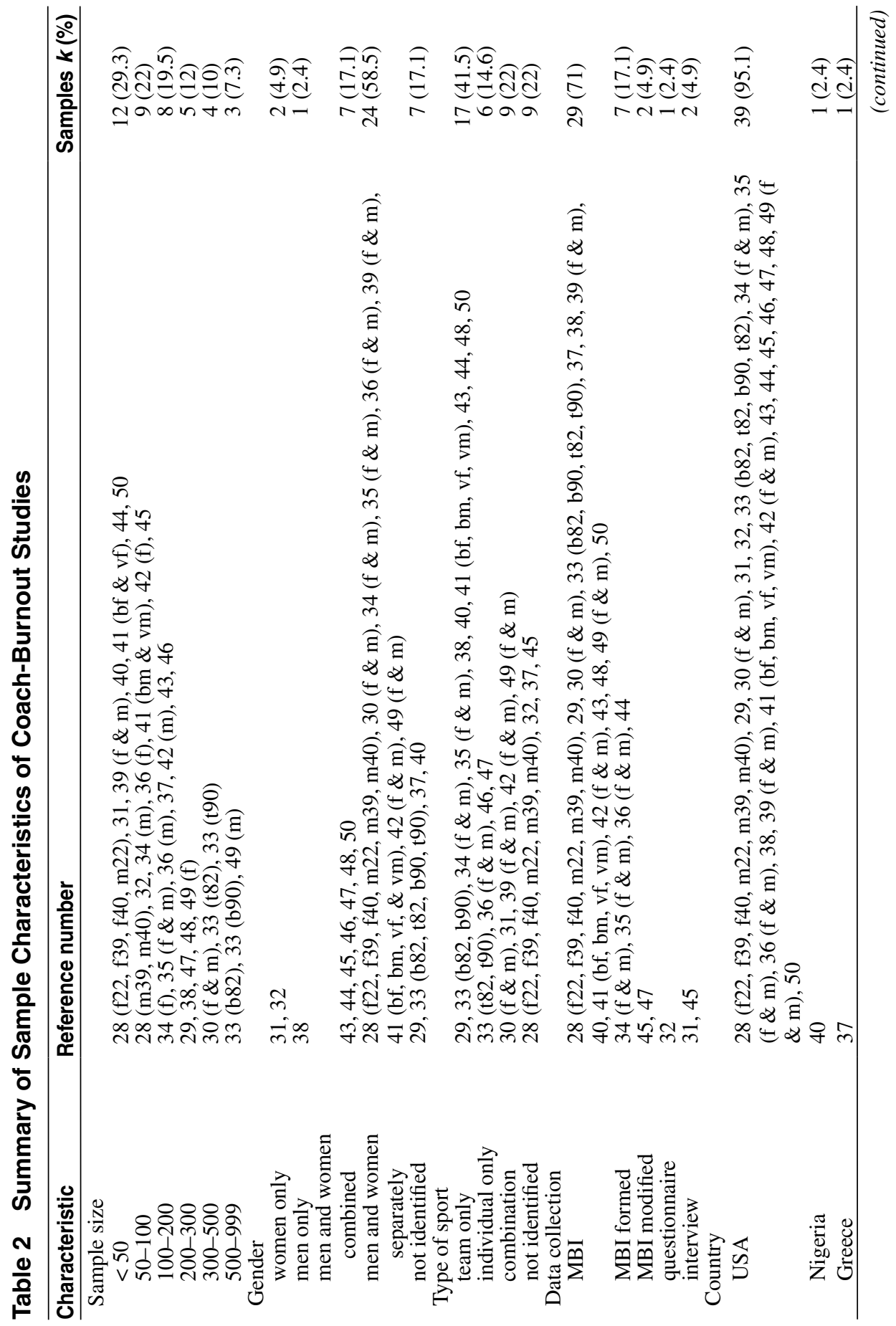




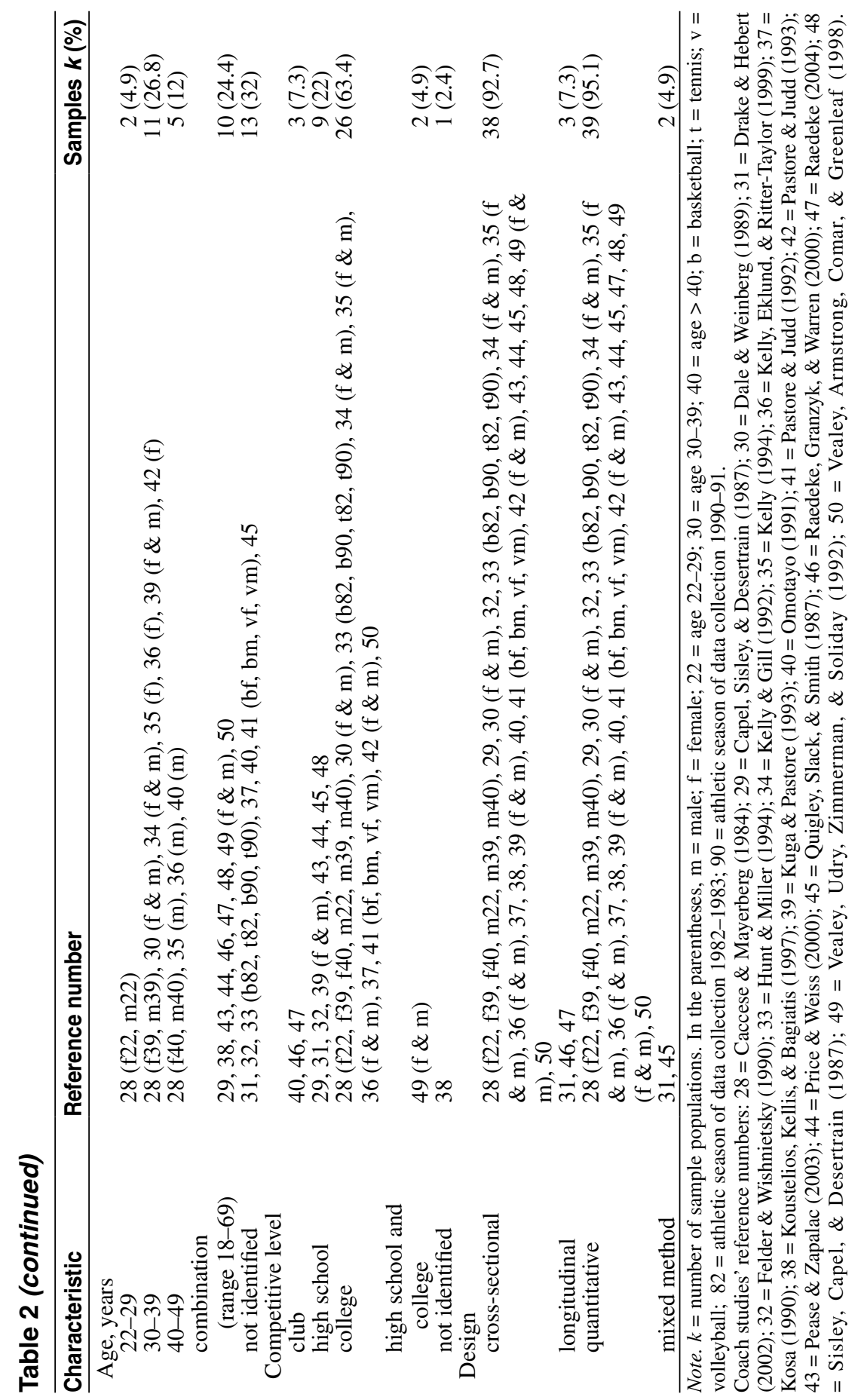




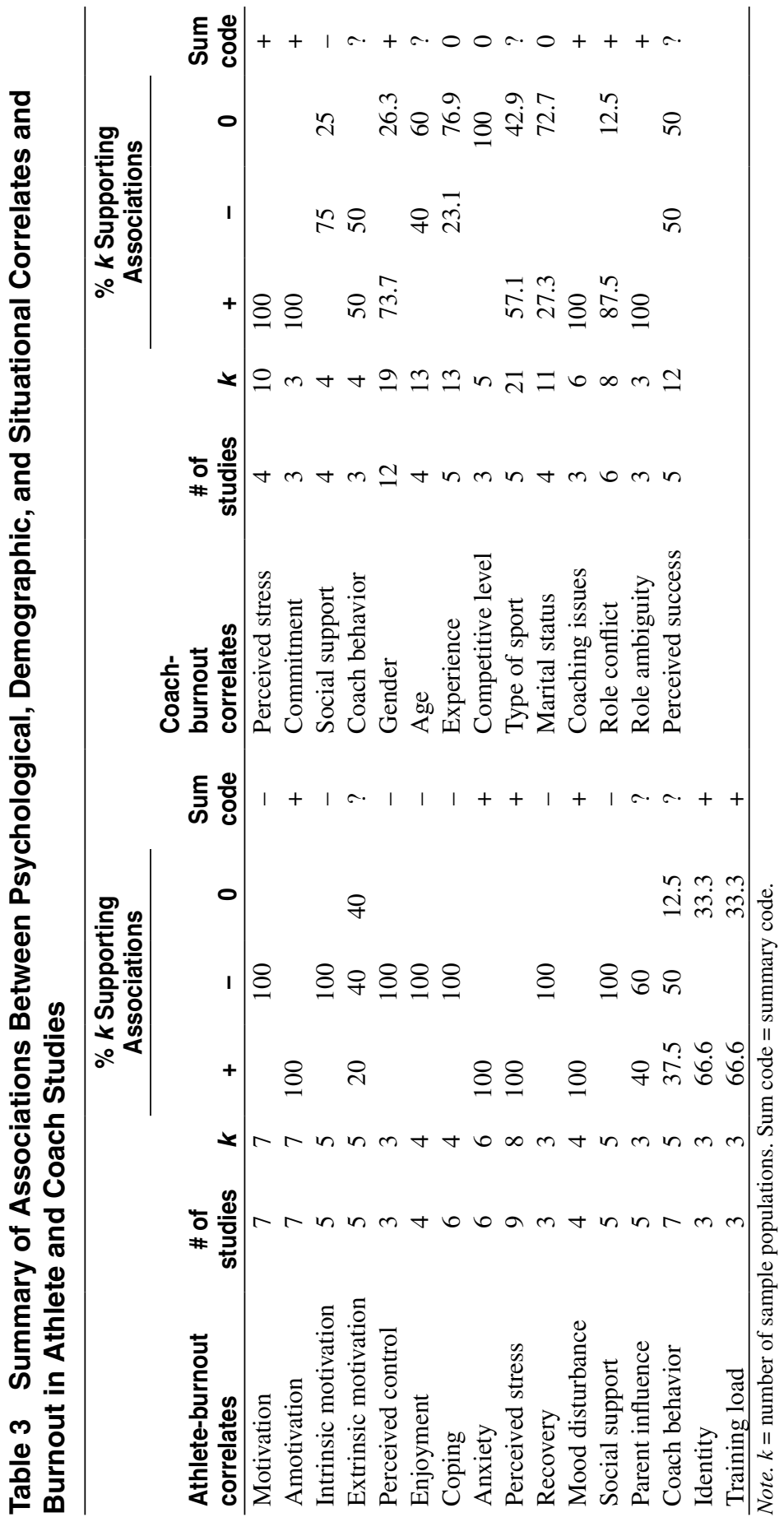


Motivation. The theme of motivation incorporated motivation, enjoyment, and perceived control. Motivation studies examined types of motivation and motivational loss. Amotivation was positively associated with burnout (100\%), and intrinsic motivation was negatively associated with it $(100 \%)$. These trends were also consistent when we examined motivation in relation to the three dimensions of burnout (i.e., physical/emotional exhaustion, reduced sense of accomplishment, and sport devaluation). The pattern for extrinsic motivation was less clear but generally ranged from no association to small, negative associations. In studies that did report a negative association it was, in most instances, with reduced sense of accomplishment. Enjoyment displayed a moderate or strong negative association $(100 \%)$, with strongest associations being recorded for sport devaluation (100\%). Athletes who felt in control and experienced greater autonomy reported lower burnout (100\%). This negative association held true for each dimension in studies by Raedeke (1997) and Cresswell and Eklund (2004) that specifically examined perceived control in relation to each dimension.

Coping With Adversity. Anxiety, perceived stress, and coping were grouped under the theme of coping with adversity. In studies that reported anxiety in relation to the three dimensions $(k=3)$, associations were positive for each one. Investigations by Tenebaum et al. (2003), Raedeke and Smith (2001, Study 3), Price and Weiss (2000), and Vealey et al. (1998) all suggested that higher levels of trait anxiety predisposed athletes to the risk of burnout. Studies exploring perceived stress have traditionally included measures of general stress (e.g., perceived-stress scale; Cohen, Kamarck, \& Mermelstein, 1983). More recent research (e.g., Jurimae, Maestu, Purge, Jurimae, \& Soot, 2002; Kellmann, Altenberg, Lormes, \& Steinacker, 2001; Kentta, Hassmen, \& Raglin, 2001), however, has begun to employ a multifaceted conceptualization of stress to include general, emotional, and social stress and both training and nontraining stress. In all studies $(k=8)$ stress was positively associated with burnout (100\%). The relationship between different types or sources of stress and the dimensions of burnout, however, have received little attention.

Coping was negatively associated with burnout in all studies (100\%). The athletes equipped with stronger coping resources were better able to handle the demands placed on them and, subsequently, were less susceptible to burnout. To date, the research has not identified the specific type of coping strategies that might help safeguard an athlete from burnout or the relationship between coping and different dimensions of burnout. Raedeke and Smith (2004) sought to explore how coping resources influenced the relationship between stress and burnout. They examined competing hypotheses - coping resources have a stress-mediating relationship versus coping resources are stress moderating-and concluded that the relationship was stress mediating, which is when burnout is influenced indirectly through the impact of coping resources on stress.

Responses to Training and Recovery. Response to training and recovery has been a relatively recent thrust of research, but it is not entirely new. The impact of training on the incidence of burnout has long been examined in the physiological literature and was first introduced explicitly to the burnout-in-sport literature through Silva's (1990) model of negative training response. Monitoring of training and overtraining has been based largely on the profile of mood states (McNair, Lorr, \& Droppleman, 1971). A positive mental-health profile is associated with successful 
athletic performance, whereas mood disturbance and a negative profile are indicative of overtraining (Kellmann \& Gunther, 2000). We identified three studies $(k=$ $3)$ that examined recovery and burnout and four studies $(k=4)$ exploring mood. Recovery was shown to be negatively associated (100\%) and mood disturbance positively associated (100\%) with burnout.

Role of Significant Others. Significant others who have been examined in the context of athlete burnout include coaches and parents. Limited attention, however, has been focused on other social groups such as peers and teammates. Findings on the impact of coach and parent behavior on athlete burnout have been mixed, and an association is indeterminate. Studies have generally reported the association between significant others and burnout and not the interaction. When the interaction is reported, it emerges that these individuals might act as potential buffers who are able to moderate demands placed on athletes by acting as much-needed sources of social support (Udry et al., 1997). Equally, unrealistic expectations, criticism, and pressure to perform vocalized by coaches and parents are potential stressors. Studies $(k=5)$ providing data on the association between social support and the three burnout dimensions reported a $100 \%$ negative association for social support and physical/emotional exhaustion and reduced sense of accomplishment and 75\% for sport devaluation.

Identity. Identity has been explored in three studies $(k=3)$, but there is insufficient information to determine an association. What the literature does reveal, however, is a potentially positive association. Gould and colleagues (1996a, 1997) reported higher mean athletic-identity scores for tennis players who had experienced burnout when compared with non-burned-out players, but this difference was not statistically significant. Through his qualitative research, which led to the publication of the unidimensional identity-development and external-control model, Coakley (1992) added further support to the association between higher burnout levels and higher athletic identity. Raedeke (1997), however, found a negative relationship between identity and each of the burnout dimensions.

\section{Demographic and Situational Correlates of Athlete Burnout}

Few repeated examinations of demographic or situational variables have been undertaken in studies on athletes. As a result, we only identified one potential situational correlate - training load or volume - and no demographic. With the exception of a study by Gould et al. (1996a, 1996b), all other studies ( $k=2$; Kellmann, et al., 2001; Kentta et al., 2001) reported a positive association between training load or volume and burnout.

\section{Qualitative Athlete-Burnout-Research Summary}

We identified seven studies that have employed a qualitative approach $(k=5)$. For amotivation $(+)$, extrinsic motivation (?), intrinsic motivation $(-)$, coping $(-)$, perceived stress (+), perceived control (-), social support (-), and parental influence (?), qualitative associations were similar to quantitative ones. Cohn's (1990) examination of stress and burnout in high school golfers and Coakley's (1992) exploration of the burnout experiences of young athletes are the only entirely qualitative studies; 
other research has employed mixed-method approaches. Qualitative methods as a whole remain relatively unused.

\section{Psychological Correlates of Coach Burnout}

Four psychological correlates of coach burnout emerged from a possible 20. Perceived stress $(100 \%)$ was positively associated with burnout, whereas commitment $(100 \%)$ and social support (75\%) were negatively associated with it. In the three studies $(k=4)$ examining coach and leadership behavior and burnout, different instrumentations were used to assess types of behavior. This made it difficult to compare findings, and, as a result, it was not possible to determine an association.

\section{Demographic Correlates of Coach Burnout}

Six demographic correlates of coach burnout emerged, including gender, age, marital status, experience, and type of sport. Our ability to draw useful conclusions was limited, however, by a lack of sufficient data and inconsistency in the quality of reporting in some studies.

The findings for gender were mixed, but a general trend emerged that female coaches experienced higher emotional exhaustion ( $73 \%$ females higher, $0 \%$ males higher, $27 \%$ no gender difference) than male coaches. The situation is less clear for reduced performance accomplishment, with a larger percentage of samples indicating no gender differences (60\% no difference). When differences were reported, women expressed greater reduced performance accomplishment $\quad 40 \%$ females higher, $0 \%$ males higher). A lack of a significant gender difference is also the main outcome for the depersonalization dimension ( $73 \%$ no difference). For age, experience and marital-status findings were also mixed-associations were indeterminate or there was no association. Although the pattern of association for age is indeterminate or not related at present, there is some evidence of burnout levels being higher in younger coaches (40\% samples), which is consistent with the professional literature (Schaufeli \& Buunk, 2003). Examinations of types of sport were also inconclusive (57.1\% positive, $42.9 \%$ no association).

\section{Situational Correlates of Coach Burnout}

Three situational variables emerged as correlates of burnout: coaching issues (e.g., timetabling and budgets), role conflict, and perceived success (including win-loss record). Both coaching issues and role conflict were strongly positively associated $(100 \%)$ and were linked to levels of perceived stress reported by coaches. Perceived success $(50 \%)$ was indeterminate.

\section{Qualitative Coach-Burnout-Research Summary}

Two studies (viz., Drake \& Hebert, 2002; Quigley, Slack, \& Smith, 1987) have employed mixed-method approaches that incorporated qualitative tools. Quigley et al. sought to examine levels of burnout and their relationship to the following factors among secondary school teacher-coaches: social support $(-)$, gender $(+$; females scored higher), age $(-)$, size of school $(-)$, compensation (lack of; + ), 
recognition (lack of; + ), rewards (lack of; + ), marital status (single; + ), perceived success $(-)$, role conflict $(+)$, and role ambiguity $(+)$. Drake and Hebert detailed case studies of two female teacher-coaches. Role conflict was a major theme in the study and was examined in relation to both inter- and intrarole conflict. Interrole conflict refers to conflicting professional demands (i.e., number of sports coached), whereas intrarole conflict concerns conflicts in other life domains (i.e., home). Social support and effective coping strategies to reduce the incidence of burnout were also explored.

\section{Research Designs}

\section{Research Designs of Athlete-Burnout Studies}

Table 1 displays a summary of data collection and research designs employed in athlete studies. The dominant research tool is the self-report measure (91\%), and eight different instruments of this nature have been used. Because the athleteburnout literature comprises only 27 studies, the large number of instruments used relative to this narrow empirical base reduces the scope for comparisons across research. Interviews are the second-most-used method, occurring in seven studies $(18.2 \%)$, and are generally part of a mixed-method approach and are a relatively underused resource.

Two new instruments that have begun to gain popularity are the athlete-burnout questionnaire (ABQ; Raedeke \& Smith, 2001) and RESTQ-Sport (Kellmann \& Kallus, 2001). Adopting Maslach and Jackson's (1984) tridimensional conceptualization of burnout, the ABQ measures physical and emotional exhaustion, reduced athletic accomplishment, and sport devaluation. Research employing the ABQ has reported acceptable internal consistency (Cresswell \& Eklund, 2004; Radeke \& Smith). The RESTQ-Sport (Kellmann \& Kallus) is designed to measure the frequency of stress and recovery activities in athletes through a multifaceted framework of emotional, cognitive, behavioral or performance, social, and physical aspects of both stress and recovery over a 3-day recall period (and is based on the stressrecovery model proposed by Kallus \& Kellmann, 2000). The burnout dimensions of emotional exhaustion and personal accomplishment form two subscales of the instrument, but devaluation is not included. High test-retest reliability has been consistently demonstrated over the 3-day period (Kellmann et al., 1997; Kellmann \& Gunther, 2000).

Most research has been cross-sectional (72.7\%) and correlational. Longitudinal work has varied significantly in the time frame for data collection ( 6 days to 1 year). Experimental designs have been used in investigations examining responses to training and recovery in relation to burnout (e.g., Tenebaum et al., 2003), but, to date, there has been limited use of such methods.

\section{Research Designs of Coach-Burnout Studies}

Self-report measures have been equally prominent in coach-burnout studies (95.1\%). In $95.4 \%$ of samples the MBI (Maslach \& Jackson, 1984) has been the instrument of choice, and through the advancement of newer versions, including the MBIGeneral, some of the earlier contextual limitations appear to have been overcome. 
The literature is inconsistent, however, in detailing the versions of the scale used or procedures followed for calculating and reporting burnout scores, which, again, hinders opportunities for comparisons across studies. Use of qualitative approaches has been highly limited (Drake \& Hebert, 2002; Quigley, et al., 1987) and, when used, is derived from an initial quantitative screening with a follow-up interview. There are no entirely qualitative studies to date. Following trends in research on athletes, most studies (92.7\%) have been cross-sectional and correlational. Drake and Hebert carried out multiple interviews over several months but did not examine changes in burnout over time. Kelley (1994) and Raedeke (2004) published the only longitudinal studies. Kelley examined changes in burnout at Time 1 (early season) and Time 2 (late season) and reported higher levels at Time 2. In a 1-year follow-up study, Raedeke (2004) elected to only employ the emotional-exhaustion dimension in examining commitment and burnout. Findings indicated a positive correlation between entrapment and feelings of emotional exhaustion.

\section{Discussion}

We identified 58 studies, most of which focused on coaches and athletes. Interest focused largely on coaches until the 1990s when Cohn (1990) and Silva (1990) offered the first investigations on athletes. Although a burgeoning body of research, the empirical base remains small. This point is even more significant when we consider the fact that the professional literature now boasts more than 6,000 publications (Schaufeli \& Buunk, 2003).

\section{Sample Characteristics}

Although interest in research on athletes has begun to emerge in Europe and Australasia, the dominance of North American samples has restricted opportunities for cross-cultural comparisons, which could aid the generalizability of findings. Research from the professional literature reports significant cultural differences in the levels of and factors associated with burnout (Maslach, Schaufeli, \& Leiter, 2001; Schaufeli \& Enzmann, 1998). Another sampling issue is the exploration of burnout in specific populations as defined by demographic factors such as age, type of sport, or competitive level. There is a cautionary note worth mentioning at this juncture, however-it is not the demographics of such populations that contribute to burnout but rather the social environment around them. Mirroring professional research, sport psychology has tended to treat demographic variables as potential causes or consequences of burnout when they are, in fact, neither. As an example, age does not cause burnout, but, rather, conditions associated with it such as personal experiences and life stage contribute to feelings of being burned-out (Schaufeli \& Enzmann). Empirical investigations of targeted groups could play an important role in the identification of those at risk and the development of prevention and management strategies.

Two final but related points on sampling are accessibility of samples and the "healthy-worker effect" (Schaufeli \& Enzmann, 1998). Ease of access to samples is an issue shared with the professional literature. In the sport literature this is most evident for studies on coaches in which predominantly coaches from an educationrelated context (i.e., high school, college, etc.) have been investigated (which is where researchers might have their best connections). There is a notable absence 
of elite coaches. Access to samples is complicated further by the healthy-worker effect. Schaufeli and Enzmann explain that this is a pitfall of burnout research and essentially concerns the use of samples that might not contain participants who have experienced burnout (because those individuals are likely to have left the sport or activity already). The authors further propose that this leads to underestimation of the syndrome. Prevalence data are highly limited in the sport domain, but Gould and Dieffenbach (2002), using data from Raedeke's (1997) study, concluded that $1-5 \%$ of the sample $(n=236)$ experienced burnout. Although an issue related more to research designs, the challenge of locating those who are experiencing burnout is further exacerbated by the correlational group-comparison nature of most sportburnout research. Such reporting means, ultimately, that affected individuals might become lost in the crowd and, with it, the actual burnout experience. Collectively, these issues necessitate more purposeful sampling in future research to enhance understanding and the generalizability of findings and, perhaps more crucially, to ensure that research is actually focused on individuals who have experienced burnout.

\section{Correlates of Burnout in Sport}

The three groups of correlates identified by the review (i.e., psychological, demographic, and situational) display similarities to those reported in the work-related literature. Researchers in the professional context describe four main groups of correlates: biographical (e.g., age), personality (e.g., hardiness), work-related attitudes (e.g., high expectations), and work and organizational (e.g., workload; Schaufeli \& Enzmann, 1998). It becomes apparent across studies on athletes and coaches, however, that there is a divergence in the emphasis of the research investigating these two populations. Among athletes, burnout has been examined much more as an individual psychological phenomenon, whereas research on coaches has tended to align more closely with the foci of the professional literature. Situational factors have been examined as the primary correlates of burnout in the work context for the last 25 years (Maslach et al., 2001), and a psychosocial perspective has been prominent in driving research forward. There has been a psychosocial thread from early athlete-burnout studies (Coakley, 1992; Gould et al., 1996a, 1996b, 1997), and more recent research has begun to adopt this perspective (e.g., Cresswell \& Eklund, 2004; Kentta et al., 2001; Price \& Weiss, 2000), but the relationship between an athlete's environment and burnout remains underresearched. The proposition here is not simply to move away from a dispositional approach in which burnout might be considered a personality weakness or a result of an aversive environment but, instead, to investigate the interplay between these factors.

With regard to psychological correlates of athlete burnout, research over the last decade, in particular, has contributed much to the knowledge base. It is typical for athletes experiencing burnout to be characterized by motivational loss shown as reduced intrinsic motivation or amotivation, a lack of enjoyment, possession of poor or ineffective coping skills, high perceived stress and anxiety, and mood disturbance associated with responses to training and nontraining stress and insufficient recovery. They perceive low social support, with significant others as either potential stressors or buffers against stress. Research examining athletic identity is limited, but there is indication of a positive association with burnout. Considerably less is known about psychological correlates of coach burnout, but what 
does emerge is that it is associated with higher levels of perceived stress related to situational factors such as coach issues and role conflict, an entrapment-based commitment profile, and low social support. In spite of the research attention that has been devoted to demographic and situational factors in coach research, the lack of consistency in the reporting of findings inhibits a useful summary of what is known about these factors and coach burnout.

Although more research has been undertaken and through it more knowledge has been gained about athlete and coach burnout since the earlier reviews by Fender (1989) and Dale and Weinberg (1990), this does not necessarily parallel understanding of burnout in the sport context. This observation stems from what is best described as a scattergun approach in the literature. We determined that a considerable number of psychological, demographic, and situational factors have been examined, but this has too often only occurred in one or two investigations. As alluded to earlier, the literature displays breadth but a notable lack of depth. In addition, it was not possible to calculate useful effect sizes in the review because of the limited repeated investigations that have occurred and inconsistency in the reporting of findings. There are significant issues for consideration here in relation to the caveats in the conceptual thinking around burnout. If the traditional theories of burnout (e.g., Coakley, 1992; Silva, 1990; Schmidt \& Stein, 1991; Smith, 1986) are considered for a moment, it is only through the work of researchers such as Gould et al. (1996a) and Raedeke and colleagues (Raedeke, 1997; Raedeke, 2004; Raedeke, Granzyk, \& Warren, 2000) that these conceptual frameworks have been specifically examined. This is not to say that there are no alternative frameworks or good reasons for investigating the correlates that have been examined to date. Jackson, Schwab, and Schuler (1986) warned 20 years ago in the context of workrelated burnout, however, that more data did not automatically bring with them more knowledge or understanding.

\section{Research Designs}

Historically, two major stumbling blocks to the advancement of the burnout-in-sport literature have been the absence of an agreed-on definition (Dale \& Weinberg, 1990; Fender, 1989) and a valid measurement tool (Raedeke \& Smith, 2001). Efforts have been made to address this through the development of an athlete-specific definition (Raedeke et al., 2002) and the operationalization of this definition through the ABQ (Raedeke \& Smith). Previously, Smith's (1986) definition of burnout as “a psychological, emotional and at times physical withdrawal from a formerly pursued and enjoyable activity in response to excessive stress or dissatisfaction" (p. 39) had been the popular definition applied to research on athletes and, to a lesser extent, research on coaches, which also used Maslach and Jackson's (1984) definition. Through the development of Raedeke et al's definition of athlete burnout, there is now greater consensus and, with it, parity of what constitutes burnout in the sport context. For the sport psychology practitioner this provides a common language that can be used in education directed toward preventing burnout, as well as in supporting individuals experiencing burnout and their social network, which is integral to this support process (Udry et al., 1997).

A potential issue for sport-burnout researchers to consider, however, is the ongoing debate in the professional domain-is there a need for three dimensions 
when emotional exhaustion has been identified as the most salient? Proponents of the three dimensions argue that it offers "conceptual richness" (Leiter, 1993) and that a unidimensional perspective creates the potential for losing "sight of the phenomenon entirely" (Maslach et al., 2001, p. 403). In the sport context the question might be raised of how to differentiate between a fatigued athlete and a burned-out athlete if only physical and emotional exhaustion are assessed. Furthermore, multiple dimensions of burnout offer the opportunity to explore profiles of the syndrome as demonstrated in the work literature (Schaufeli \& Enzmann, 1998). The establishment of profiles could further the inquiry into different strains of burnout that have been proposed in the sport literature (viz., Gould et al., 1996b, 1997). Such strains have significant implications to both the academic exploration of burnout and applied practice.

Similar to the early professional literature, the methodological quality of early burnout-in-sport research has been varied (Schaufeli \& Buunk, 2003). It is only recently that athlete-specific instruments have been published (i.e., ABQ and RESTQ-Sport), and although the literature on coaches has used the MBI, a range of versions has been employed with a lack of standardization in the reporting of findings. Qualitative approaches are limited and tend to involve an initial screening process of participants through the completion of a self-report measure. There are only two entirely qualitative studies in the literature (viz., Coakley, 1992; Cohn, 1990). Both Fender (1989) and Dale and Weinberg (1990), however, advocated the use of multimethod approaches, which included self-report, interviews, and observation. In the work context there has also been strong argument for the use of interviews and observation (Leiter, 1993).

The most popular strategy for data collection in the literature has been a selfreport instrument of burnout as part of a cross-sectional and correlational design. Two important issues arise from this approach, however. First, if self-report measures are to continue to be the dominant tool, an important area for future research is the production of norms to abet the identification of individuals with burnout. Although there is now a specific athlete-burnout instrument (i.e., ABQ), it is not yet clear what composes burnout using this measure. In the work context norms have been established for the MBI across a range of occupations, not only aiding identification but also facilitating comparisons between populations and negotiating the healthy-worker effect (Schaufeli \& Enzmann, 1998). The establishment of such norms would aid not only academic enquiry but also the work of practitioners. Second, the prevalence of cross-sectional correlational studies and the absence of longitudinal approaches have largely prevented the exploration of causality and created a perspective of burnout as a state rather than the chronic process by which it is also defined. Although a process approach does appear in some coach research (viz., Quigley et al., 1987; Vealey et al., 1992), the tendency to adopt a state perspective has, on one hand, facilitated the identification of factors associated with burnout but, on the other, has delimited understanding of cause-and-effect mechanisms. If burnout is to be identified early and treated effectively, we must understand more about how it manifests itself.

Finally, research design is an area previously touched on in relation to correlates, namely conceptual thinking and the systematic testing of theories. Unlike the professional literature, which witnessed an era of "sophisticated" methodology in the 1990s that sought to specifically explore and test theoretical explanations of 
burnout (Maslach et al., 2001), little systematic testing and deliberate exploration of athlete-burnout models (either traditional or contemporary) has taken place.

\section{Limitations}

The growth in systematic reviews has, in part, been born out of dissatisfaction of more traditional reviews, which tend to be descriptive and are seldom able to make sense of the collection of studies reviewed (Noblit \& Hare, 1988). It is not without limitations, however. Concerns have been raised over search, inclusion and exclusion criteria, and potential sources of bias including publication and language (Stern \& Simes, 1997). Although an extensive literature search was undertaken to identify all published studies, using only published data in the English language is acknowledged as a limitation. During the electronic and manual searches, however, a significant number of foreign-language studies did not emerge.

\section{Conclusion}

The burnout-in-sport literature has seen a steady growth over the last 20 years, although the empirical base remains relatively small. Renewed interest since 2000 has led to significant advances in the research on athletes, in particular, and a state of buoyancy in the release of publications is currently evident. After conducting the review we asked what we had learned about burnout and sport. The answer is much, but, equally, there is still much to explore. In summary of "what we know," the following are key features and advancements of the literature: (a) two significant research branches for athlete burnout and coach burnout, (b) some consensual agreement on multidimensional conceptualizations of burnout, (c) self-report measures specific to athletes and to coaches, (d) a range of theoretical frameworks to explain burnout in sport, and (e) identification of correlates of burnout in athletes and coaches. Returning to the original reviews conducted by Fender (1989) and Dale and Weinberg (1990) in which key future research directions were identified (as outlined in the introduction to this review), there appears to have been considerable development in relation to the definition, measurement, and theoretical conceptualization of burnout. Research focusing on interventions, however, remains largely unexplored, with no published studies of this nature to date. Although the progress that has been made and the current enthusiasm for research in the area reflect exciting times, there is much to learn from the historical development of the literature. From its inception, burnout has been a term that has resonated with people both in the professional domain (in which it originated) and other life domains such as sport (into which it has been extended). Its popularity and use as an all-encompassing concept (Schaufeli \& Buunk, 2003), however, actually led to initial criticism and the perception of burnout in the work- and health-psychology literature as a form of "pop psychology." In sport psychology's enthusiasm to embrace and explore the concept of burnout, there might be evidence, certainly in early studies, of falling victim to the burnout-popularity trap. Often described as something that is easier to observe than define (Gould, 1997), this feature of burnout has almost certainly affected its conceptualization and the robustness of findings. Smith (1986), in his influential article that introduced the cognitive affective-stress model, raised the pertinent question of the extent to which the nature, causes, and consequences of 
athlete burnout are unique and the extent to which they are shared by those who suffer burnout in other domains. This question remains unanswered, but through the advancement of athlete- and coach-specific definitions and measurement tools, the field has moved farther forward toward an answer.

With regard to "what we need to know" and potential future directions, we identified the following key themes: (a) research examining burnout among sport practitioners including athletic trainers, directors, and officials, as well as purposeful sampling based on demographic factors such as gender, sport, level, and age group; (b) cross-cultural investigations; (c) greater exploration of burnout as a psychosocial phenomenon and the impact of the individual's social environment; (d) development of alternative assessment measures (i.e., observation, performance indicators) and multimethod strategies for examining burnout; (e) systematic testing of theoretical frameworks and development of existing and new perspectives; (f) more longitudinal research to investigate causal relationships and the burnout process; (g) more qualitative research to further understanding of the individual experiences of burnout; and (h) development, testing, and evaluation of intervention studies for the prevention, treatment, and rehabilitation of individuals who have experienced burnout.

Along with these areas there are a number of new perspectives that have recently emerged in the literature that are likely to feature significantly in future research. The work that has examined the complex relationship between burnout, overtraining, staleness, stress, recovery, coping, and mood (e.g., Kallus \& Kellmann, 2000; Kentta \& Hassmen, 1998) will contribute much to clarifying the conceptual confusion that has existed between them. In particular, the terms burnout, overtraining, and staleness have often been used interchangeably and, hence, inaccurately, and making clear distinctions, as well as identifying the overlap, is important to not only the advancement of research but also the education of sport practitioners (e.g., coaches, athletics directors), parents, and athletes. A possible drawback to this work, however, is its continuation of a stress-induced perspective of burnout that has traditionally dominated the literature. Non-stress-induced perspectives have been offered (viz., Coakley, 1992; Schmidt \& Stein, 1991), but these are still underresearched in comparison. The exploration of self-determination theory has more recently emerged as an alternative to stress approaches and a possible framework for understanding the relationship between burnout and motivational loss that is associated with the syndrome (Cresswell \& Eklund, 2005a, 2005b).

Perhaps most significant, the review process has highlighted how a previous lack of exploration of theoretical frameworks, differences in the conceptualization of burnout, and measurement strategies employed have affected the ability of research to offer informed explanations for how burnout manifests itself, affects individuals, and, arguably the most crucial aim of this research, how it can be prevented and treated and how individuals can be rehabilitated. Recent reconsideration of what composes burnout and how to measure it, however, has contributed to greater consensus in the field regarding approaches to examining it. In relation to applied practice, this could provide a more cohesive knowledge base from which to develop effective monitoring, intervention, and management strategies. 


\section{References}

Bar-Eli, M., Shirom, A., Nir, M., \& Pines, A.M. (2004). Role conflict and burnout among elite Israeli female athletes engaged in feminine and non-feminine sports. Women in Sport and Physical Activity Journal, 13(2), 39-50.

Booth, A. (2001, May). Cochrane or cock-eyed? How should we conduct systematic reviews or qualitative research? Paper presented at the Qualitative Evidence-Based Practice Conference, Taking a Critical Stance, Leeds, UK.

Caccese, T.M., \& Mayerberg, C.K. (1984). Gender differences in perceived burnout of college coaches. Journal of Sport \& Exercise Psychology, 6, 279-288.

Capel, S.A., Sisley, B.L., \& Desertrain, G.S. (1987). The relationship of role conflict and role ambiguity to burnout in high school basketball coaches. Journal of Sport Psychology, 9, 106-117.

Coakley, J.A. (1992). Burnout among adolescent athletes: A personal failure or social problem. Sociology of Sport Journal, 9, 271-285.

Cohen, S., Kamarck, T., \& Mermelstein, R. (1983). A global measure of perceived stress. Journal of Health and Social Behavior, 24, 385-396.

Cohn, P. (1990). An exploratory study on sources of stress and athlete burnout in youth golf. The Sport Psychologist, 4, 95-106.

Cresswell, S.L., \& Eklund, R.C. (2004). The athlete burnout syndrome: Possible early warning signs. Journal of Science and Medicine in Sport, 7, 481-487.

Cresswell, S.L., \& Eklund, R.C. (2005a). Motivation and burnout among top amateur rugby players. Medicine and Science in Sports and Exercise, 37, 469-477.

Cresswell, S.L., \& Eklund, R.C. (2005b). Changes in athlete burnout and motivation over a 12-week league tournament. Medicine and Science in Sports and Exercise, 37, 1957-1966.

Dale, J., \& Weinberg, R.S. (1989). The relationship between coaches leadership style and burnout. The Sport Psychologist, 3, 1-13.

Dale, J., \& Weinberg, R.S. (1990). Burnout in sport: A review and critique. Applied Sport Psychology, 2, 67-83.

Drake, D., \& Hebert, E.P. (2002). Perceptions of occupational stress and strategies for avoiding burnout: Case studies of two female teacher coaches. The Physical Educator, 59, 170-183.

Feigely, D.A. (1984). Psychological burnout in high-level athletes. The Physician and Sports Medicine, 12, 109-119.

Felder, D., \& Wishnietsky, D. (1990). Role conflict, coaching burnout and reduction in the number of female interscholastic coaches. The Physical Educator, 47(2), 7-13.

Fender, L.K. (1989). Athlete burnout: Potential for research and intervention strategies. The Sport Psychologist, 3, 63-71.

Fothergill, A., Edwards, D., \& Burnard, P. (2004). Stress, burnout, coping and stress management in psychiatrists: Findings from a systematic review. International Journal of Social Psychiatry, 50, 54-65.

Freudenberger, H.J. (1974). Staff burnout. Journal of Social Issues, 30, 159-165.

Gould, D. (1997). Burnout: Personal motivation gone awry. Journal of Applied Sport Psychology, 7, 176-189.

Gould, D., \& Dieffenbach, K. (2002). Overtraining, underrecovery, and burnout in sport. In M. Kellman (Ed.), Enhancing recovery: Preventing underperformance in athletes (pp. 25-35). Champaign, IL: Human Kinetics.

Gould, D., Tuffey, S., Udry, E., \& Loehr, J. (1996a). Burnout in competitive junior tennis players: I. Quantitative psychological assessment. The Sport Psychologist, 10, 322-340.

Gould, D., Tuffey, S., Udry, E., \& Loehr, J. (1996b). Burnout in competitive junior tennis players: II. Qualitative analysis. The Sport Psychologist, 10, 341-366. 
Gould, D., Tuffey, S., Udry, E., \& Loehr, J. (1997). Burnout in competitive junior tennis players: III. Individual differences in the burnout experience. The Sport Psychologist, $11,257-276$.

Harlick, M., \& McKenzie, A. (2000). Burnout in junior tennis: A research report. New Zealand Journal of Sport Medicine, 28, 36-39.

Hunt, K.R., \& Miller, S.R. (1994). Comparison of levels of perceived stress and burnout among college basketball and tennis coaches. Applied Research in Coaching and Athletics Annual, 9 (pp. 198-222).

Jackson, S.E., Schwab, R.L., \& Schuler, R.S. (1986). Toward an understanding of the burnout phenomenon. Journal of Applied Psychology, 71, 630-640.

Jurimae, J., Maestu, J., Purge, P., Jurimae, T., \& Soot, T. (2002). Relationships among heavy training stress, mood state, and performance for male junior rowers. Perceptual and Motor Skills, 95, 520-526.

Kallus, K.W., \& Kellmann, M. (2000). Burnout in athletes and coaches. In Y.L. Hanin (Ed.), Emotions in sport (pp. 209-230). Champaign, IL: Human Kinetics.

Kelley, B.C. (1994). A model of stress and burnout in collegiate coaches: Effects of gender and time of season. Research Quarterly for Exercise and Sport, 65, 48-58.

Kelley, B.C., Eklund, R.C., \& Ritter-Taylor, M. (1999). Stress and burnout among collegiate tennis coaches. Journal of Sport \& Exercise Psychology, 21, 113-130.

Kelley, B.C., \& Gill, D.L. (1993). An examination of personal and situational variables, stress appraisal, and burnout in collegiate tennis coaches. Research Quarterly for Exercise and Sport, 64, 94-102.

Kellmann, M., Altenburg, D., Lormes, W., \& Steinacker, J.M. (2001). Assessing stress and recovery during preparation for the World Championships in rowing. The Sport Psychologist, 15, 151-167.

Kellmann, M., \& Gunther, K. (2000). Changes in stress and recovery in elite rowers during preparation for the Olympic Games. Medicine and Science in Sports and Exercise, 32, 676-683.

Kellmann, M., \& Kallus, K.W. (2001). Recovery-stress questionnaire for athletes: User manual. Champaign, IL: Human Kinetics.

Kentta, G., \& Hassmen, P. (1998). Overtraining and recovery: A conceptual model. Sports Medicine, 26, 1-16.

Kentta, G., Hassmen, P., \& Raglin, J.S. (2001). Training practices and overtraining syndrome in Swedish age-group athletes. International Journal of Sports Medicine, 22, 460-465.

Kjormo, O., \& Halvari, H. (2002). Relation of burnout with lack of time for being with significant others, role conflict, cohesion, and self-confidence among Norwegian Olympic athletes. Perceptual and Motor Skills, 94, 795-804.

Kosa, B. (1990). Teacher-coach burnout and coping strategies. The Physical Educator, 47, 153-157.

Koustelio, A.D., Kellis, S., and Bagiatis, K. (1997). The role of family on football coaches' burnout. Coaching and Sport Science Journal, 2, 41-45.

Kuga, D.J. \& Pastore, D.L. (1993). Burnout levels in Wisconsin track and softball coaches. Journal of Wisconsin Association for Health, PE, Recreation and Dance, 22, 21-22.

Lai, C., \& Wiggins, M.S. (2003). Burnout perceptions over time in NCAA Division I soccer players. International Sports Journal, 7, 120-127.

Lee, R.T., \& Ashforth, B.E. (1996). A meta-analytic examination of the correlates of the three dimensions of burnout. Journal of Applied Psychology, 81, 123-133.

Leiter, M.P. (1993). Burnout as a developmental process: Consideration of models. In W.B. Schaufeli, C. Maslach, \& T. Marek (Eds.), Professional burnout: Recent developments in theory and research (pp. 237-250). Washington, DC: Taylor \& Francis. 
Maslach, C., \& Jackson, S.E. (1984). Burnout in organizational settings. In S. Oskamp (Ed.), Applied social psychology annual: Applications in organizational settings (Vol. 5, pp. 133-153). Beverly Hills, CA: Sage.

Maslach, C., Schaufeli, W.B., \& Leiter, M.P. (2001). Job burnout. Annual Review of Psychology, 52, 397-422.

McNair, D.M., Lorr, M., \& Droppleman, L.F. (1971). Manual for the profile of mood states. San Diego, CA: Educational and Industrial Testing Services.

Mulrow, C., Cook, D.J., \& Davidoff, F. (1997). Systematic reviews: Critical links in the great chain of evidence. Annals of Internal Medicine, 126, 389-391.

Noblit, G.W., \& Hare, R.D. (1988). Meta-ethnography: Synthesizing qualitative studies. Beverly Hills, CA: Sage.

Omotayo, O.O. (1991). Frequency of burnout among selected soccer coaches in Nigeria. Asian Journal of Physical Education, 14, 83-88.

Pastore, D.L., \& Judd, M.R. (1992). Burnout in two-year college coaches of women's team sports. Journal of Physical Education, Recreation and Dance, 63, 74-79.

Pastore, D.L., \& Judd, M.R. (1993). Gender differences in burnout among coaches of women's athletic teams of 2-year college. Sociology of Sport Journal, 10, 205-212.

Pease, D.G., \& Zapalac, R.K. (2003). Burnout in high school varsity basketball coaches. Texas Coach, 47(1), pp. 30-31.

Price, M.S., \& Weiss, M.R. (2000). Relationships among coach burnout, coach behaviors, and athletes' psychological responses. The Sport Psychologist, 14, 391-409.

Quigley, T.A., Slack, T., \& Smith, G.J. (1987). Burnout in secondary school teacher coaches. Alberta Journal of Educational Research, 34, 260-274.

Raedeke, T.D. (1997). Is athlete burnout more than just stress? A sport commitment perspective. Journal of Sport \& Exercise Psychology, 19, 396-417.

Raedeke, T.D. (2004). Coach commitment and burnout: A one year follow-up. Journal of Applied Sport Psychology, 16, 333-349.

Raedeke, T.D., Granzyk, T.L., \& Warren, A. (2000). Why coaches experience burnout: A commitment perspective. Journal of Sport \& Exercise Psychology, 22, 85-105.

Raedeke, T.D., Lunney, K., \& Venables, K. (2002). Understanding athlete burnout: Coach perspectives. Journal of Sport Behavior, 25, 181-206.

Raedeke, T.D., \& Smith, A.L. (2001). Development and preliminary validation of an athlete burnout measure. Journal of Sport \& Exercise Psychology, 23, 281-306.

Raedeke, T.D., \& Smith, A.L. (2004). Coping resources and athlete burnout: An examination of stress mediated and moderation hypothesis. Journal of Sport \& Exercise Psychology, 26, 525-541.

Reinboth, M., \& Duda, J.L. (2004). The motivational climate, perceived ability, and athletes' psychological and physical well-being. The Sport Psychologist, 18, 237-251.

Sallis, J.F., Prochaska, J.J., \& Taylor, A.C. (2000). A review of correlates of physical activity of children and adolescents. Medicine and Science in Sports and Exercise, 32, 963-975.

Schaufeli, W.B., \& Buunk, B.P. (2003). Burnout: An overview of 25 years of research and theorizing. In M.J. Schabracq, J.A.M. Winnubst, \& C.L. Cooper (Eds.), The handbook of work and health psychology (2nd ed., pp. 383-425). New York: John Wiley \& Sons.

Schaufeli, W.B., \& Enzmann, D. (1998). The burnout companion to study and practice: A critical analysis. London: Taylor \& Francis.

Schmidt, G.W., \& Stein, G.L. (1991). A commitment model of burnout. Journal of Applied Sport Psychology, 8, 323-345.

Silva, J.M. (1990). An analysis of the training stress syndrome in competitive athletics. Journal of Applied Sport Psychology, 2, 5-20.

Sisley, B.L., Capel, S.A., \& Desertrain, G.S. (1987). Preventing burnout in teachers and coaches. Journal of Physical Education, Recreation and Dance, 58, 71-75. 
Smith, R.E. (1986). Toward a cognitive-affective model of athlete burnout. Journal of Sport Psychology, 8, 36-50.

Stern, J.M., \& Simes, R.J. (1997). Publication bias: Evidence of delayed publication in a cohort study of clinical research projects. British Medical Journal, 315, 640-645.

Tenebaum, G., Jones, C.M., Kitsantas, A., Sacks, D.N., \& Berwick, J.P. (2003). Failure adaptation: An investigation of the stress response process in sport. International Journal of Sport Psychology, 34, 27-62.

Udry, E., Gould, D., Bridges, D., \& Tuffey, S. (1997). People helping people? Examining the social ties of athletes coping with burnout and injury stress. Journal of Sport \& Exercise Psychology, 19, 368-395.

Vealey, R.S., Armstrong, L., Comar, W., \& Greenleaf, C.A. (1998). Influence of perceived coaching behaviors on burnout and competitive anxiety in female college athletes. Journal of Applied Sport Psychology, 10, 297-318.

Vealey, R.S., Udry, E.M., Zimmerman, V., \& Soliday, J. (1992). Intrapersonal and situational predictors of coaching burnout. Journal of Sport \& Exercise Psychology, 14, 40-58.

Weed, M. (2005). Meta interpretation: A method for the interpretive synthesis of qualitative research. Qualitative Social Research, 6(1). Retrieved September 19, 2006, from www. qualitative-research.net/fqs/ 